\title{
Reverse logistics: A study of bullwhip in continuous time
}

\author{
Li Zhou, Stephen M. Disney, Chandra S. Lalwani \\ Logistics System Dynamics Group, Cardiff Business School \\ Cardiff University \\ Aberconway Building, Colum Drive, CF10 3EU, UK \\ zhoul@cardiff.ac.uk
}

\begin{abstract}
A simple dynamic model of a hybrid manufacturing / remanufacturing system is developed. In particular the model is used to study an infinite horizon, continuous time, APIOBPCS (Automatic Pipeline Inventory and Order Based Production Control System) model. We specifically highlight the effect of remanufacturing lead-time and the return rate on the bullwhip produced by the ordering policy. Our results clearly show that a larger return rate leads to less bullwhip, thus returns can be used to absorb demand fluctuations to some extent. Longer remanufacturing lead-times have less impact at reducing bullwhip than shorter lead-times. We conclude, within our specified system, that bullwhip is always less with returns than without returns.
\end{abstract}

Index Terms - manufacturing, remanufacturing, bullwhip ,return rate.

\section{INTRODUCTION}

Both customers and regulatory authorities are increasingly insisting that manufacturers reduce the amount of environmental waste generated by their production process. Leading companies are focusing on product reuse and reverse logistics as a means of gaining competitive advantage [1]. They may even remanufacture their products to make them essentially as good as new. However, managing such a reverse supply chain involves many uncertainties, especially those concerned with the quantity, quality and timing of the returned products [2]. In a number of recent papers, many issues have been raised, such as how to design a product so that it is easy to be disassembled and reused [3], or how to make decisions on product recovery [4] [5], for example reselling, recovery, or disposal. The recovery option may also include repair, refurbishing, remanufacturing, cannibalization and recycling [6].

This paper will focuses on a scenario where the "used" products are pushed through a remanufacturing process as soon as they are returned from the marketplace. There is a lead-time associated with the time to remanufacture a product and also a lead-time associated with the time that a product is "in use" by the customer. For convenience, we will join these two lead-times together and called it $\mathrm{Tr}$, the Time to Remanufacture. Furthermore, we assume this remanufacturing lead-time is a stationary stochastic variable drawn from an exponential distribution. Only a fraction, $0 \leq k \leq 1$ of demand is returned from the marketplace, the rest we assume is either unusable or is lost to a landfill. We also assume the

\author{
HeLei Wu \\ Information Engineering School \\ Nanchang University \\ Nanchang, Jiangxi Province, China \\ Wuhelei2000@163.com
}

remanufactured products are "as good as new" and thus form part of the serviceable stock. Serviceable stock is the finished goods from which customer demand is satisfied. We assume here that the customer demand is a stationary, independently and identically distributed random process. Our analysis is independent of the distribution of the stochastic customer demand. That is, for example, demand could be drawn from a normal, log normal, exponential or a gamma distribution. The manufacture of new products is controlled by a variant of the Order-Up-To policy [7]. Fig. 1 illustrates the material flow in this manufacturing / remanufacturing supply chain. We note that this system is different to the push/pull system of [8].

Much of the recent literature on supply chains has been concerned with the "bullwhip" problem [9]. This is where the orders at the supplier level tend to have a larger variance than sales to the buyer (that is the demand gets distorted), and the distortion propagates upstream in an amplified form (i.e. variance amplification) [10]. Reference [11] has summarized the negative impact of bullwhip problem as follows; excessive inventory investments throughout out the supply chain to cope with the increased demand variability, reduced customer service due to the inertia of the production/distribution system, lost revenues due to shortages, reduced productivity of capital investment, increased investment in capacity, inefficient use of transport capacity and increased missed production schedules. Thus, avoiding or reducing bullwhip has a real and important impact on the performance of a commercial company.

Reference [12] provides a review of quantitative models in reverse logistics. The aim of this paper is to contribute to this field by using control theory as a medium for analysis by highlighting the bullwhip phenomenon in a reverse logistics scenario with respect to the return rate and the remanufacturing lead-time. The paper is organized as follows. First, we give a formal definition of our model and derive the corresponding continuous time, Laplace transfer function of

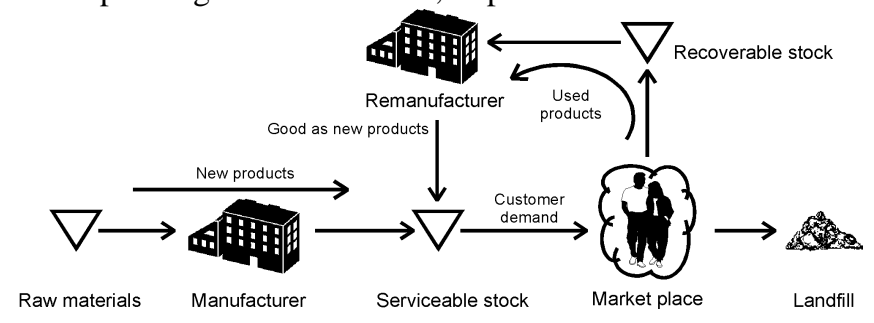

Figure 1. Material flow in a simple manufacturing / remanufacturing system 
Zhou, L., Disney, S.M., Lalwani, C.S. and Wu, H.L., (2004) "Reverse logistics: A study of bullwhip in continuous time", The $5^{\text {th }}$ World Congress on Intelligent Control and Automation, June 14-18, Hangzhou, China.

the remanufacturing supply chain. Section 3 presents an analytical expression for bullwhip. We then compare the bullwhip performance of the remanufacturing supply chain with the traditional supply chain. Section 4 concludes.

\section{MODEL DESCRIPTION}

In our analysis, we assume that time passes continuously and we exploit the Laplace transform in our analysis. The manufacturer's replenishment order is placed to produce new product based on a forecast of future demand, the serviceable inventory and the current work in progress in the original equipment factory, see Figure 2. The ordering policy that we study here is based upon an infinite horizon, continuous time, APIOBPCS model. The APIOBPCS is an acronym for Automatic Pipeline Inventory and Order Based Production Control System [13]. The APIOBPCS policy can be expressed in words as; let the production targets are equal to the sum of mean demand, plus a fraction $(1 / T i)$ of the inventory error, plus a fraction $(1 / T w)$ of the WIP error.

However, the remanufacturing scenario requires a slight modification to the classical APIOBPCS policy as shown in Figure 2. Here a fraction $(k)$ of the demand is returned, brought to a good as new condition and added to the net stock of serviceable inventory, after a random delay, drawn from an exponential distribution with an average of $T r$ time units. Recall we are assuming that the demand is a stationary i.i.d. random process. This means the minimum mean squared error forecast of all future demands is given by the long-term expected value of demand. Furthermore, as we are considering a linear system, we may assume without loss of generality, the mean demand is zero for simplicity.

We may rearrange Figure 2 using standard techniques (see Ref. [14] for an introduction) to obtain the order rate transfer function,

$$
\frac{O R}{D}=\frac{(1+s T p)(1-k+s T r) T w}{(1+s T r)(T w+s T i(T p+T w+s T p T w))} .
$$

All of the constants in the system may be assumed to be greater than zero, so we have $T i \quad 0, T p \quad 0, T w \quad 0, T r \quad 0$, and $0 \quad k 1$.

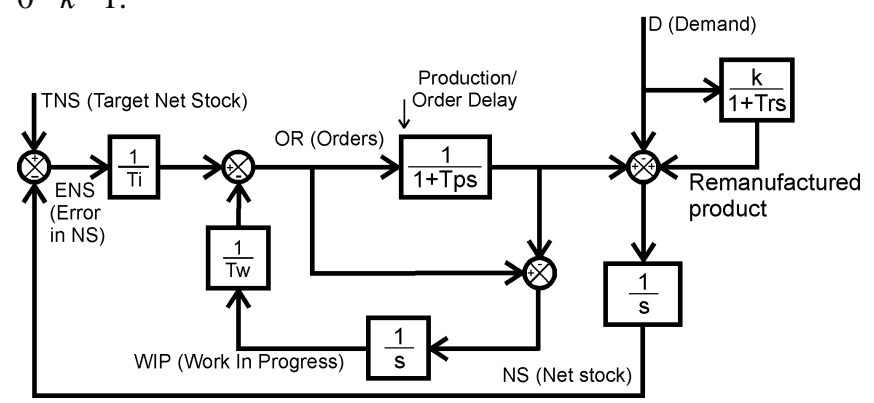

Figure 2 Block diagram of our remanufacturing system
A formal definition of bullwhip, that we will adopt here, has been proposed by [15] as,

Bullwhip $=\frac{\sigma_{O R}^{2}}{\sigma_{D}^{2}}$.

By applying Parseval's theory (details omitted for brevity, we refer interested readers to Ref. [16] ), bullwhip for the general system shown in Figure 2 can be shown to be,

Bullwhip $=\frac{T w\left[\begin{array}{l}\operatorname{Tr}^{2}(T i+T p) T w+ \\ (k-1)^{2} T i T p(T i+T p) T w+ \\ T r T i\left((k-1)^{2} T i+T p\right)(T p+T w)\end{array}\right]}{\left[\begin{array}{l}2 T i^{2}(T p+T w) \\ \left(T i T p T r+T r^{2} T w+T i(T p+T r) T w\right.\end{array}\right]}$.

As (3) is quite complex, lets first review some special cases. By setting $k=0$, we may determine the bullwhip in a traditional supply chain. This is shown in (4). Recall, Ti and $T w$ are control parameters that we may used to tune the dynamic response of the system and $T p$ is the lead-time associated with the manufacture of new product.

Bullwhip $_{k=0}=\frac{T w(T i+T p)}{2 T i^{2}(T p+T w)}$.

(4) reveals that in a supply chain with no returns, the leadtime, $T p$, should be reduced in order to smooth production and reduce the associated capacity on-costs. An important subset of the control parameters occurs when, $T w=T i$. It allows further simplification to (3) and (4), as shown in (5) and (6) respectively.

$$
\begin{aligned}
& \text { Bullwhip }_{T w=T i}=\frac{(k-1)^{2} T i+T r}{2 T i(T i+T r)}=\frac{1}{2 T i}+\frac{k^{2}-2 k}{2(T i+T r)} \\
& \text { Bullwhip }_{k=0, T w=T i}=\frac{1}{2 T i}
\end{aligned}
$$

Here we can see that when $T w=T i$, that is, when the two feedback gains are equal, then bullwhip in a remanufacturing supply chain will always be less than in a traditional supply chain. This is because we assume $0 k 1$, thus the last term of (5) is always negative. (5) and (6) show that when $T w=T i$, $T p$ drops out of the bullwhip expressions.

When all of the products are returned from the marketplace (after the stochastic exponential delay), $k=1$. Here (3) reduces to,

Bullwhip $_{k=1, T w=T i}=\frac{1}{2 T i}-\frac{1}{2(T i+T r)}$,

where we can clearly see that; bullwhip in a remanufacturing supply chain is always less than in a traditional supply chain, but this smoothing effect is reduced with longer remanufacturing lead-times, $T r$. Returning now to the general case of (3). We may factor this into the following,

\section{BullWhiP ANALYSIS Of THE REVERSE LOGISTICS SCENARIO}


Zhou, L., Disney, S.M., Lalwani, C.S. and Wu, H.L., (2004) "Reverse logistics: A study of bullwhip in continuous time", The $5^{\text {th }}$ World Congress on Intelligent

$$
\begin{aligned}
\text { Bullwhip }= & \frac{(T i+T p) T w}{2 T i^{2}(T p+T w)}+\frac{(k-2) k T w}{2 T i(T p+T w)}+ \\
& \frac{(k-2) k(T p-T r)(T p+T r) T w^{2}}{2 T i(T p+T w)\left(T i T p T r+T r^{2} T w+T i(T p+T r) T w\right)}
\end{aligned}
$$

In (8) the first term on the right hand side is the bullwhip generated by a traditional supply chain. The second term is always negative as $0 \quad k \quad 1$. Interestingly, the third term is; zero when $T r=T p$ and $T r=-T p$, negative when $T r<T p$ and positive when $T r>T p$. The sum of the last two terms is always negative for positive remanufacturing lead-times, $T r$, which we obviously may assume is true. This leads us to investigate bullwhip when the remanufacturing lead-time (this also includes the time the product is in the hands of the user) is the same as the manufacturing lead-time. When $T r=T p$, (3) becomes,

$$
\text { Bullwhip }_{T r=T p}=\frac{\left((k-1)^{2} T i+T p\right) T w}{2 T i^{2}(T p+T w)} \text {. }
$$

(9) is always less than (4). Returning again to (3), differentiating (3) with respect to $k$ and $T r$ yields;

$$
\begin{aligned}
& \frac{\partial \text { Bullwhip }}{\partial k}=\frac{\left[\begin{array}{l}
{[(k-1) \operatorname{Tw}(T p(T i+T p) T w+} \\
\operatorname{Tr} T i(T p+T w))
\end{array}\right]}{\left[\begin{array}{l}
\operatorname{Ti}(T p+T w) \\
\left(\operatorname{Tr}{ }^{2} T w+T i T p T w+T r T i(T p+T w)\right)
\end{array}\right]}, \\
& \frac{\partial \text { Bullwhip }}{\partial T r}=\frac{\left(\begin{array}{l}
(1-k) T w^{2}(2 T r T p(T i+T p) T w+ \\
\left.\operatorname{Tr}^{2} T i(T p+T w)+T i T p^{2}(T p+T w)\right)
\end{array}\right)}{\left(\begin{array}{l}
T i(T p+T w) \\
\left(T r^{2} T w+T i T p T w+T r T i(T p+T w)\right)^{2}
\end{array}\right)} .
\end{aligned}
$$

(10) is monotone and always negative (or zero when $k=1$ ) in the return rate, $k$. (11) is monotone and positive (or zero when $k=1)$ in the remanufacturing lead-time, $T r$.

The relationship of bullwhip between return rate $k$ and manufacturing lead-times, Tr, can be illustrated in Fig. 3 when we set $T p=3, T i=4$, and $T w=8$.

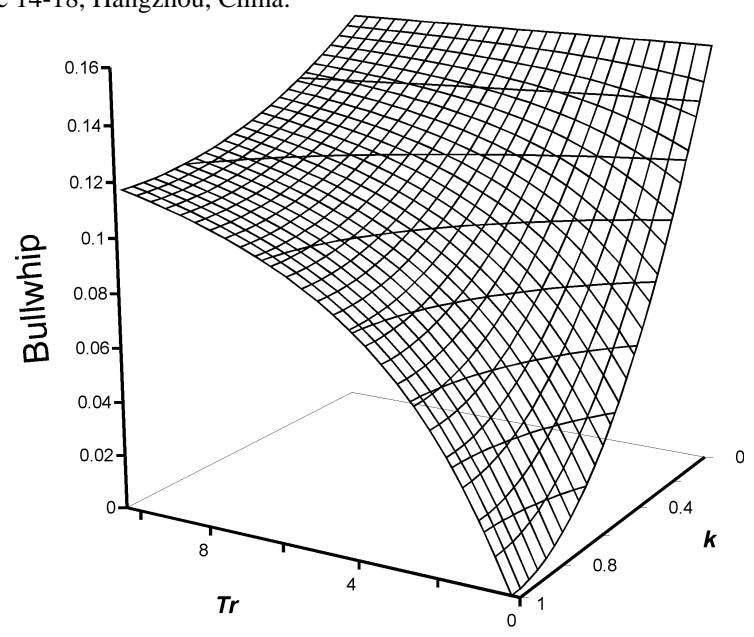

Fig. 3. The effect of return rate and lead-time on bullwhip

For our analysis we have used Mathematica (Wolfram Research ( ${ }^{\circledR}$ Illinois) is assist in the algebra and verified our results via numerical integration in Matlab (®) The MathWorks, Inc). Our analysis broadly supports the results of [17] which has adapted the beer game [18] to include a reverse logistics scenario. Initial results from [17] also suggest that remanufacturing reduces bullwhip in a supply chain.

\section{CONCLUSIONS}

We have analyzed a stylized manufacturing / remanufacturing supply chain that reclaims (remanufactures) product to "as good as new", as soon as it is available. The manufacturer tops up serviceable inventory by production of new products. The model presented in this paper has been developed using block diagrams, Laplace transforms and Parseval's relation. Our findings show that the returned products reduce the bullwhip experienced by the manufacturer of original equipment compared to a manufacturer in a supply chain without remanufacturing or reverse logistics. This means that reverse flows can be used to improve the efficiency of supply chains. Thus product recovery not only benefits the environment but may also have economical effects. However, longer remanufacturing lead-times have less impact at reducing bullwhip compared to shorter remanufacturing lead-times.

\section{REFERENCES}

[1] B. Mahadevan, D.F. Pyke, and M. Fleischmann, "Periodic review, push inventory policies for remanufacturing," European Journal of Operational Research vol. 151 (3), pp.536-551, 2003.

[2] M.A. Seitz, S.M. Disney, M.M. Naim, "Managing product recovery operations: The case of automotive engine remanufacturing," EUROMA POMS Conference, Como Lake, Italy, vol. 2, pp.1045-1053, June 2003.

[3] Y. Kondo, K. Deguchi, Y. Hayashi, "Reversibility and disassembly time of part connection," Resources, Conservation and Recycling, vol. 38, pp.175-184, 2003.

[4] E. van der Laan, M. Salomon, "Production planning and inventory control with remanufacturing and disposal," European Journal of Operational Research, vol. 102, pp.264-278, 1997. 
Zhou, L., Disney, S.M., Lalwani, C.S. and Wu, H.L., (2004) "Reverse logistics: A study of bullwhip in continuous time", The ${ }^{\text {th }}$ World Congress on Intelligent Control and Automation, June 14-18, Hangzhou, China.

[5] R.H. Teunter, D. Vlachos, "On the necessity of a disposal option for returned items that can be remanufactured," International Journal of Production Economics, vol. 75, pp. 257-266, 2002.

[6] M. Thierry, M. Salomon, J. van Nunen., L. van Wassenhove, "Strategic issues in product recovery management," California Management Review, vol. 37 (2), pp. 114-135, 1995.

[7] J. Dejonckheere, S.M. Disney, M.R. Lambrecht, and D.R. Towill, "Measuring and avoiding the bullwhip effect: A control theoretic approach," European Journal of Operational Research, vol. 47 (3), pp. 567-590, 2003.

[8] E. van der Laan, M. Salomon, R. Dekker, "An investigation of leadtime effects in manufacturing/remanufacturing systems under simple PUSH and PULL control strategies," European Journal of Operational Research, vol. 115, pp. 195-214, 1999.

[9] H.L. Lee, P. Padmanabhan, S. Whang, "Information distortion in a supply chain: the Bullwhip Effect," Management Science, vol. 43 pp. 543-558, 1997.

[10] J. Dejonckheere, S.M. Disney, M.R. Lambrecht, and D.R. Towill, "Transfer function analysis of forecasting induced bullwhip in supply chains," International Journal of Production Economics, vol. 78 (2), pp. 133-144, 2002.

[11] C. Carlsson, and R. Fuller, "Fuzzy approach to the bullwhip effect," Proceedings of the $15^{\text {th }}$ European Meeting on Cybernetics and Systems Research, Vienna, pp. 228-233, April 2000.

[12] M. Fleischmann, J. Bolemhof-Ruwaard, R. Dekker, E. van der Laan, J. van Nunen, L. Van Wassenhove, "Quantitative models for reverse logistics: a review," European Journal of Operational Research, vol. 103, pp.1-17, 1997.

[13] S. John, M.M. Naim, and D.R. Towill, "Dynamic analysis of a WIP compensated decision support system," International Journal of Manufacturing system Design, vol.1(4), pp. 283-297, 1994.

[14] N.S. Nise, Control systems engineering. California, Benjamin/Cummings, 1994.

[15] Y.F. Chen, Z. Drezner, J.K. Ryan, D. Simchi-Levi, "Quantifying the Bullwhip effect in a simple supply chain: The impact of forecasting, lead-times and information," Management Science, vol. 46, pp. 436$443,2000$.

[16] G.C. Newton, L.A. Gould, J.F. Kaiser, Analytical design of linear feedback controls. John Wiley \& Sons, pp. 39-51, 1957.

[17] J.H. Wang, "Adaptation of the beer game to reverse logistics," MSc Thesis, Cardiff Business School, Wales, UK, 2002.

[18] J. Sterman, "Modelling managerial behaviour: Misperceptions of feedback in a dynamic decision making experiment," Management Science, vol. 35(3), pp. 321-339, 1989. 